\title{
Some Doubts About Argument by Hypothetical
}

\author{
Paul H. Robinson $\dagger$
}

In his paper, Why the Successful Assassin Is More Wicked than the Unsuccessful One, ${ }^{1}$ Leo Katz "pick[s] up the gauntlet [Sandy] Kadish throws down" to offer a nonconsequentialist justification for giving significance to resulting harm and, in particular, to justify the common practice of pumishing attempts less than the completed offense. ${ }^{2}$

In one sense, I may not be the ideal person to serve as critic. I am not one of those who, like Kadish and others, does not believe in the significance of resulting harm in assessing blameworthiness (people whom Katz calls the "luck-skeptics" but to whom I will refer as the "nonbelievers" in the significance of resulting harm). ${ }^{3}$ I will try to perform the mental gymnastics of pretending to be a nonbeliever as I evaluate Professor Katz's arguments. As Part I explains, I fear the nonbeliever will be unpersuaded.

Whatever the outcome of the debate as Professor Katz presents it, the method of his argument raises issues that I think are just as interesting as its outcome. My social science work, as limited as it is, gives me pause when assessing the argument-by-hypothetical method that Professor Katz uses so ingeniously here (and elsewhere). ${ }^{4}$ Relatedly, I have some doubts about using our intuitions in the way Professor Katz would have us use them here (and elsewhere), or at least doubts about whether we can draw from them the kind of conclusions about moral desert that Professor Katz would have us draw.

Setting aside these two concerns for a moment, let me consider Professor Katz's arguments on their own terms.

Copyright () 2000 California Law Review, Inc. California Law Review, Incorporated (CLR) is a California nonprofit corporation. CLR and the authors are solely responsible for the content of their publications.

$\dagger \quad$ Edna \& Ednyfed Williams Professor of Law, Northwestern University.

1. 88 CALIF. L. Rev. 791 (2000).

2. Id. at 792 .

3. The label "luck-skeptic" is admirably short but is ambiguous. Is the "luck-skeptic" skeptical of relying upon or of rejecting moral luck? Also, by focusing on "luck" the label seems a bit too narrow. There could be any number of reasons that turns one to believe that resulting harm is insignificant.

4. For a recent example, see Leo Katz, Ill-Gotten Gains: Evasion, Biackmail, Fraud, ANd Kindred Puzzles of THE LAW (1996). See also Leo Katz, Bad Acts and Guizty Minds: Conundrums of the Criminal LaW (1987). 
Katz's Argument to Persuade The "Nonbeliever" of The Significance of Resulting HaRm: A CRitique in Katzian Terms

Without some intervening argument, a nonbeliever in the significance of resulting harm would draw the following conclusions about Professor Katz's four central hypotheticals. I use the phrase "attempts/kills" below to recognize the nonbeliever's view that an unsuccessful attempt to kill and an intentional killing are of equal blameworthiness.

Larry: intends to kill five people, then saves them from death by killing one other, which adds up to six attempts/kills

Michael: intentionally kills five people (he is not as bad as Larry because only five attempts/kills rather than six)

Stephen: attempts unsuccessfully to kill five people (he is as bad as Michael because same five atteinpts/kills; not as bad as Larry)

Larry Jr.: intends only aggravated assault of five people, whom he saves from death by killing one (he is not as bad as any of the above because only one attempt/kill, rather than five or six; his five aggravated assaults add blameworthiness, but not enough to make up for the four atteinpts/kills that he is short compared to Michael and Stephen)

Professor Katz intends to persuade the nonbeliever that atteinpts should be punished less than completed offenses. He must do this without relying upon the nonbeliever's intuitions about the significance of resulting harm, of course, for this would just lead to the ranking above. He explains that he intends to persuade by:

show[ing] the [nonbeliever ('luck-skeptic')] that a variety of OTHER intuitions which he has (other, that is, than the intuition that attempts and completed offenses should be treated alike) should lead hin to want to treat attempts and completed offenses differently. He is of course free to decide that the intuitions that led him to such a conclusion are less dear to him than the intuition that attempts and completed offenses deserve to be treated alike, but that will be the price, and my guess is that the price is too high: the intuitions to which I am appealing seem to me quite powerful and hard to give up. ${ }^{5}$

His general strategy is to show that $A 1>A 2$ and $A 2>A 3$, therefore it must follow that $A I>A 3$ :

A1: Michael (completed) > A2: Larry and Larry Jr. > A3: Stephen (attempt)

5. Email from Leo Katz to Paul H. Robinson (Sept. 21, 1999) (on file with author) (hereinafter Katz e-mail]; see also Katz, supra note 1, at 794 ("I will try to show the greater wickedness of the successful assassin to follow from other dearly held moral intuitions that no one would want to do without."). 
Professor Katz has little difficulty in making two points. First, there seems agreement from all points of view that:

Michael (kills five) > Larry Jr. (kills one, five aggravated assaults)

Second, Katz can easily show, no matter what one's view, that:

Larry (five attempts, one kill) > Stephen (five attempts)

Both believers and nonbelievers will agree to this, although for different reasons. The nonbeliever in the significance of resulting harm sees six units of wrongdoing versus five. The believer im the significance of resulting harm sees Larry's side of the equation as having an additional killing.

The crunch comes when Professor Katz tries to establish that:

Larry = Larry $J$.

To prove this, he offers a particular variation of the Larry and Larry Jr. hypotheticals, in which the mental story leading up to the moment of poisoning is slightly different:

Case 1. Larry Jr. cannot decide whether to poison his five victims outright, or whether to save them after he has poisoned them, by carving up a sixth. Seconds before administering the poison, he decides he is going to save then by carving up a sixth.

Case 2. Larry cannot decide whether to poison his five victims outright, or whether to save them after he has poisoned them, by carving up a sixth. Seconds after administering the poison, he decides he is going to save thein by carving up a sixth. ${ }^{6}$

Professor Katz assumes the nonbeliever will agree that the two cases are about the same or at least very similar because the only difference between the two is that one comes to the decision (to save, by killing an innocent) a few seconds later than the other. Larry Jr. decides to save just seconds before the poisoning. Larry decides just seconds after the poisoning. Except for a difference in timing of a few seconds, the two are identical. Professor Katz is banking on the fact that such slight differences in the timing of the decision cannot justify treating the cases differently. And, if the two cases are of equal blameworthiness, he has made his case:

If Michael (completed) $>$ Larry, and

Larry Jr. > Stephen (attempt), and

Larry $=$ Larry $J r$. then

Michael (completed) > Stephen (attempt).

Q.E.D.

But I fear that the critical "Larry = Larry Jr." link is weak. The nonbeliever's original assessment of these two cases puts Larry as the worst of the four cases and Larry Jr. as the least bad. Will all that change because of the timing argument?

6. Katz, supra note 1, at 803 . 
Apparently Professor Katz suspects the nonbeliever has little interest in the concurrence requirement, which would have us gauge the defendant's culpability not at some miscellaneous time but at the time of his conduct constituting the offense. ${ }^{7}$ But if the nonbeliever does believe in the concurrence requirement, Katz is sunk, because the Larry-vs.-Larry-Jr. cases will be seen as having noticeably different levels of blameworthiness, even under Katz's "close timing" variations. At the time of the poisoming, Larry Jr. has no intention to kill; he has already decided to save the five by killing another. Larry's intention as to causing the deaths is left unclear. We are told he cannot decide whether to save or not. Only after the poisoning does he decide to save. I have little trouble guessing that a jury would conclude on these facts that Larry had the intention to kill at the time he poisoned. The fact that he had in his mind a second possibility, an alternative to the killing - that is, saving the five by killing a sixth-would not be likely to vitiate the presence of an intent to kill as one of two alternatives in his mind. Every person has a variety of purposes and intentions when they act. We commonly ignore many if not most of these and ask only whether the purposes he does have include the purpose that the law says makes the conduct criminally condemnable. ${ }^{8}$

Professor Katz is right, of course, that if one equates attempts and completed offenses, as the nonbeliever does, it is not entirely obvious that the concurrence requirement is still important in the same way. Those who do believe in the significance of resulting harm have good reason to look to the particular point in timie of the conduct causing the result. Causation has special importance to them. But for those who do not believe in the significance of resulting harm-those who equate attempts with the completed offense-any point along the continuum of conduct toward an offense might seem as relevant as the conduct causing the result. And that indifference to timing is ingeniously exploited by Professor Katz in his "close timing" cases. The nonbeliever's ambivalence about application of a concurrence requirement is the insight behind Professor Katz's argument.

Ultimately, however, I think the argument fails. One who does not believe in the significance of resulting harm might nonetheless believe in the concurrence requirement. There is nothing in believing resulting harm insignificant that forbids reliance upon concurrence. The moment of the conduct that causes the prohibited result may not be as special for the nonbeliever as it is for the believer, but it might be useful and important nonetheless to the nonbeliever.

7. For a discussion of the concurrence requirement, see PAUL H. RoBINSON, CRIMINAL LAW 217-18 (1997).

8. In a related way, the law treats a conditional intention as an intention nonetheless. See, e.g., Model Penal Code $§ 2.02(6)$ (1985). 
Our reasons for adopting a concurrence requirement have little to do with the significance or insignificance of resulting harm. Enforcing concurrence with some defined moment allows us to have a fixed point in time to associate witl the offense, which may be important for a variety of reasons. For example, it provides a necessary point of reference for such collateral inatters as jurisdiction, venue, and statutes of limitations. More importantly, a concurrence requirement helps focus criminal law on blameworthy conduct rather than blameworthy character. It avoids basing criminal liability on a bad intention that might have occurred at some miscellaneous time and limits liability to those people who act upon their bad intention. Where the intention is condemnable because it is an intention to cause death-for example, by poisoning-why not pick as the necessary point in time the inoment at which the actor engages in the conduct that will cause the death and chooses in fact to do the poisoning?

Even if a concurrence requirement does not effectively serve its desired purposes in every instance, the nonbeliever might nonetheless prefer a system that commits itself to such a requirement and therefore might be willing to apply such a requirement even in the odd or bizarre case in which it does not seem to advance significantly the character-vs.-conduct distinction. ${ }^{9}$

What hurts Professor Katz's argument even more is the fact that, whatever one thinks the nonbeliever might do about the concurrence requirement, it seeins clear that there is nothing in that issue that is a "dearly held moral intuition" $"$ that, in order to retain, he or she would feel coinpelled to give up the view that resulting harm is insignificant. There is nothing in the concurrence issue that could be a "price . . too high" to pay, requiring abandonment of the view that resulting harm is insignificant. Instead, the concurrence requirement is simply a logistical device for framing our evaluation of acts, representing only a small part of our inoral evaluations of those acts. The concurrence issue in close-timing cases simply does not connect with "intuitions ... quite powerful and hard to give up,"12 as Professor Katz admits he needs in order to convince the nonbehever to abandon the view that resulting harm is insignificant. ${ }^{13}$

9. This might be the case with the special "close-timing" hypotheticals that Professor Katz presents. It is worth noting that one who believes in the significance of resulting harm must make the same kind of rough judgment about the concurrence requirement (and a variety of other issues). Some kinds of unusual cases might present confusing apphications that do not serve the requirement's larger purpose for believers, for example the peculiar fact pattern in Thabo Meli. See Thabo Meli v. The Queen, [1954] 1 W.L.R. 228, [1954] 1 All E.R. 373 (P.C.). Yet believers may retain the requirement because it normally does fine and no better principle or easily applicable rule is available.

10. Katz, supra note 1 , at 794.

11. Katz e-mail, supra note 5.

12. Id.

13. When Professor Katz and I discussed my doubts, set out in the text above, he offered an additional argument. (He was not conceding in any way that my criticisms above presented a problem 
with which he could not deal.) Although it is not included in his paper, let me set out his other argument. It uses the same "Larry intermediary" approach (but without Larry Jr.). Spccifically, it aims to persuade one who does not believe in the significance of resulting harm that Larry (six attempts/kills-attempts five + kills one) is less blameworthy than Michael (five attcmpts/kills-kills five). See Katz email, supra note 5 . If he succeeds, he can make the same move as before: If Michael > Larry and Larry > Stephen (not disputed), then Michael > Stephen.

It is another ingenious argument, I think. Hcre it is: Larry initially may seem worse than Michael, when simply comparing six versus five attempts/kills, but Larry should get credit for voluntarily renouncing his intention to kill five. And that credit, for voluntarily renouncing five killings, outweighs the blameworthiness of the additional attempt/killing that Larry has as compared to Michael.

The common law did not recognize a defense or mitigation for renunciation after the conduct constituting an offense was complete. And modern codes similarly reject any defense or rcduction in grade where the full offense conduct is complete or where the attempt conduct is complete, but admits one exception (at least the Model Penal Code does; see Model Penal Code $\S$ 5.01(4) (1985)): Where the conduct is complete but the result has not yet occurred, a defense is given, but it is given for purely practical, utilitarian reasons. See, e.g., Model Penal CoDe $\$ 5.01 \mathrm{cmt}$. at 359 (1985) (giving as the primary reasons the fact that renunciation may undcrcut the conclusion of dangerousness and may provide the actor an incentive to desist). The actor may be the person in the best position to interrupt the chain of events leading to the result, as by stamping out the bomb fuse he just lit. Nonetheless, one could construct a nonconsequentialist argument in support of at least a mitigation for renunciation, even for a renunciation coming after completion of the full offense conduct (aftcr the poisoning, on the facts here).

The question, however, is this: even if one who does not believe in the significance of resulting harm recognized such a "renunciation mitigation," would the mitigation recognized be enough to outweigh the extra attempt/kill that Larry has more than Michael? Professor Katz notes that even if the renunciation mitigation were only 20 percent, Larry gets it for each of five renunciations and therefore gets a reduction sufficient to leave him equal in blameworthiness to Michael. He then points out that even if the mitigation were less than 20 percent, he necd only increase the number of victims in his hypothetical saved by Larry's renunciation to accumulate enough mitigation to outweigh his extra attempt/kill. A 10 percent mitigation would give Larry more than enough if he renounces his intention to kill eleven victims.

But Professor Katz here assumes mitigations can be aggregated. Available data suggests that our intuitions are different. See, e.g., Paul H. Robinson \& John M. DaRley, Justice, Liability, \& Blame: Community Views aNd the Criminal Law 189-97 (1995) (Study 18: Punishment for Multiple Offenses). For example, punishment for two offenses typically is more than punishment for a single offense but noticeably less than twice the punishment for one offense. In other words, punishment for the second offense is discounted from the first. Punishment for three offenses suggests an even greater discount for the third. The United States Sentencing Guidelines use just such a discounting formulae in assessing the penalty for most multiple offenses. See U.S. SENTENCING GUIDELINES MANUAL §§ 3D1.1-3D1.5.1 (1998). The effect of its formulae is to make every additional offense count for something but increasingly less. The total penalty for multiple offenses approaches the point of double the first offense, but never reaches that point.

The saine "volume discount" effect might be expectcd as well for mitigations. Rcnunciation of one attempt/killing might entitle the offender to a mitigation of the punishment compared to that for an unrenounced attempt/killing. While renunciation for two attempts/killings also might gain a mitigation, and perhaps an even greater mitigation than for only one, the mitigation for the second is likely to be less the mitigation for the first. The mitigation discount for a third renunciation might be even less.

If renunciation mitigations cannot be aggrcgated, if, instead, additional mitigations are discounted to some extent, then Professor Katz can no longer assume that if a renunciation mitigation is recognized it will outweigh Larry's extra attempt/killing. Indeed, if the renunciation mitigation discount follows the pattcrn of the United States Scntencing Commission formulae, Larry's mitigation would never get to be more than twice the mitigation for his first renunciation. Thus, if the renuneiation mitigation were 50 percent, no matter now many killings he renounced, Larry could nevcr get to the point of outweighing one full attempt/killing, and could not get his moral ledger down to that of Michael's. There is nothing in the view of the nonbeliever in the significance of resulting harm that 
My ultimate conclusion in these arguments is that Professor Katz will fail to persuade one who does not believe in the significance of resulting harm that an attempt is less blameworthy than the completed offense.

II

\section{The Danger of Hypotheticals}

In Part I, I worked through Professor Katz's arguments on the terms on which he offered them, but I have reservations about whether the sort of argument by hypothetical he uses is a reliable method for determining people's true intuition of blameworthiness on the issues for which Katz seeks them. In this Part, I suggest the reasons for my doubts. In the next Part, I suggest a different kind of concern.

The core of Professor Katz's method is to ask the reader to form an intuition as to the degree of blameworthiness of a person in a hypothetical case and to compare that to the degree of blameworthiness of a person in a second hypothetical, and sometimes in a third, fourth, and fifth. For his argument in this paper, he summarizes his method this way:

[My approach] asks you to compare A1 with A2 (the assassin who hits versus the assassin who turns his hit into a miss) and A2 with A3 (the assassin who turns his hit into a miss versus the assassin who misses because he cannot help it). Without having to appeal to your feelings about luck, I then ... convince you that A1 is worse than $A 2$ and that $A 2$ is worse than $A 3$, whence it follow[s] that $A 1$ is worse than A3. ${ }^{14}$

My concerns with the method relate to whether such comparisons of blameworthiness can reliably be made and whether they represent the kind of blameworthiness judginent that Professor Katz assumes they do. I do not think it challenges the validity of the method of "reflective equilibrium" generally, ${ }^{15}$ but rather some common practices under that method.

Some readers may find my concerns a bit odd, coming as they do from someone who has published a book that purports to draw conclusions

suggests he or she would insist on a renunciation mitigation of over 50 percent, which is what Professor Katz must have for his argument to work if the discounting system described here were in place.

In the end, however, the greater difficulty with Professor Katz's argument is of a different sort. No matter what view the nonbeliever takes on whether to recognize a renunciation mitigation and, if so, of what effect, the renunciation issues contains no "dearly held moral intuition that no one would want to do without." Katz, supra note 1, at 794. I suspect many nonbelievers have only vague intuitions regarding a renunciation mitigation. Even if the nonbeliever had some intuition, it seems clear that it cannot be very strong. If it were, the law and literature would reflect such a view. Compare that absence of attention to the law and literature on the significance of resulting harm, and even more specifically on the grading of attempts. The nonbeliever's intuitions have been expressed and heard (as in Model Penal Code $\S 5.05(1)$ ). Where is the "dearly held moral intuition" about a renunciation mitigation that will compel the nonbeliever to turn 180 degrees to now embrace the significance of resulting harm?

14. Katz, supra note 1 , at 806 .

15. See id. at 794. 
from the study and testing of glorified hypotheticals (social scientists called them "scenarios"). ${ }^{16}$ But it is precisely this experience that makes me nervous about the way we law professors so commonly argue by hypothetical. Hypotheticals are wonderful devices of great helpfulness in our business. They allow us to strip away the infinite complexity of real life and focus on a few isolated essentials. But it is just that absence of detail that makes hypotheticals so dangerous.

When people make blameworthiness judgments, they take into account an astonishing variety of factors. ${ }^{17}$ Small facts of every sort can make a difference to a person's blameworthiness judgment, a point that Professor Katz himself makes. ${ }^{18}$ Given this kind of intuitive sophistication, it should be no surprise that, in order to make the kind of judgment for which Professor Katz (and Darley and I) ask, people want to know the "story." They want and need some basic sense of who the actors are and what has happened. Most importantly for our purposes, if the scenario does not give the basic relevant facts, readers often fill in the missing details on their own, drawing upon what "usually" is the situation or what "probably" happens in such a case, and extrapolating accordingly from the facts they are given. Because everyone's life experience is different, different people may "fill out" the story with different details. The fewer details the scenario provides, the more the reader is left to fill in. Thus, the variability of the "stories" that different readers envision is at its greatest when the scenario is at its shortest.

For scenario drafters, this malleability of the scenario's meaning is a major headache. It makes scenario drafting a major undertaking. After a set of scenarios is prepared, isolating the factors to be tested and varying them appropriately among the different scenarios, the scenarios must be field tested to determine how they are actually perceived by subjects. During this field testing, subjects commonly are not even asked the ultimate question, such as "how much liability do you think is appropriate?", but instead are asked a series of questions about what the scenarios say, "According to the scenario, did Able intend to cause the harm? How harmful was the conduct?", and so on.

These "manipulation checks," as they are called, tell the designer whether the scenario is being perceived as intended. If it is not, the facts are manipulated in a way that the designer thinks will produce the desired perception, and the instrument is retested in the field and further revised as needed. Without the quality control measure of manipulation checks, one

16. See Paul H. Robinson \& John M. Darley, Justice, Liability, \& Blame: Community Views AND THE CRIMINAL LAW (1995).

17. My work with John Darley, reported in Justice, LIABILITY, \& BlaME: CoMmunity Views AND The Criminal Law, id., only emphasizes the point.

18. See Katz, supra note 1, at n.21. 
could never know whether the subjects' reaction to a scenario is a reaction to the scenario intended by the designer or a reaction to a different set of facts derived from the subject's own particular reading.

As noted, the less information provided by the scenario, the more the subject must "read in" to create a real picture with sufficient information to inake a meaningful blameworthiness judgment. Thus, the arguinent-byhypothetical practiced by law professors is a particularly dangerous exercise because the hypotheticals tend to be thin on facts, thus inviting more uncontrolled and unknown information to be "read in."

Let me give soine examples of common problems for scenario designers. Consider the following two straightforward hypotheticals, the results of which we want to compare to test the subject's intuition about the role of resulting harm in assessing blame:

$\mathrm{X}$ hits $\mathrm{Y} . \mathrm{Y}$ is injured.

$Z$ hits $\mathrm{Y}$. $\mathrm{Y}$ dies.

What should be the extent of liability of $X$ and of $Z$ ?

Presumably, any difference in liability between the two hypotheticals shows the role of resulting harm, yes? No.

Subjects commonly read in different degrees of intentionality depending on the facts of the story. They inay read in greater intentionality in the case of a death than in the case of an imjury. The reader may assume that because $Y$ died from $Z$ 's hit but not from X's hit, $Z$ hit with a greater determination to cause $Y$ 's death, whereas $X$ inay have intended only to cause injury. The reader could make this kind of discrimination without really thinking about it, while just trying to make a good faith intuitive judgment of blameworthiness. Yet, it means that any difference im liability between the scenarios inay result from the difference in perceived intentionality rather than because of the difference in resulting harm.

Assuine you adjust the hypotheticals to control better the perception of intentionality: ${ }^{19}$

Intending to kill $\mathrm{Y}, \mathrm{X}$ hits $\mathrm{Y}$. $\mathrm{Y}$ is injured.

Intending to kill $\mathrm{Y}, \mathrm{Z}$ hits $\mathrm{Y}$. $\mathrm{Y}$ dies.

What should be the extent of liability of $X$ and of $Z$ ?

Can we assume that any difference in liability between the two hypotheticals then springs from the difference in resulting harm? Not necessarily.

A reader inay well assume that, even if the intentions of the two are the same, Z's hit involved greater force than X's. After all, $Y$ died from Z's hit but not from X's. Upon this reading, any liability difference

19. In fact, it is not always sufficient simply to tell the subjects the fact you want them to perceive. Especially when the fact is something as subjective as intention (as opposed to extent of harm), the subject may find the stated fact unbelievable and discount it. But assume for the purposes of this example that your manipulation check confirms that your revision has succeeded in controlling subjects' perceptions on intentionality. 
reported for the two hypotheticals is of little value. Greater liability for $\mathrm{Z}$ than for X might reflect the subject's view that resulting death deserves more punishment than resulting injury, all other things being equal. But it also might reflect the subject's view that, while resulting harm is irrelevant, the greater force used by $\mathrm{Z}$ deserves greater punishment. Or, it inight reflect some unknown combination of these two views.

Assume you try to avoid the problem by explicitly describing the force used in each case:

$\mathrm{X}$ hits $\mathrm{Y}$ with a stick that is one inch in diameter, breaking the stick in half. $Y$ is injured.

$\mathrm{Z}$ hits $\mathrm{Y}$ with a stick that is one inch in diameter, breaking the stick in half. $\mathrm{Y}$ dies.

What should be the extent of liability of $X$ and of $Z$ ?

Does a comparison of the blameworthiness of $X$ and $Z$ depend now entirely on the difference of resulting harm? Not necessarily.

For example, subjects commonly take account of subsequent results when they judge the extent of a prior risk. If a result actually occurs, the subject is more likely to rate its probability of occurring, as judged at an earlier time, as higher than in the case where the risked harm does not in fact coine about. In other words, the benefit of hindsight commonly alters a subject's perception of what the extent of risk must have been.$^{20}$ Thus, any difference in liability may be due in part (or in whole) to the subject's perception that $\mathrm{X}$ and $\mathrm{Z}$ have created different degrees of risk. For example, the reader may assuine that, while $X$ and $Z$ have used the same amount of force, the two struck $Y$ somewhat differently, in ways that would create different degrees of risk of death. Any difference in liability between the two hypotheticals, then, might be the result of either the perceived difference in risk created or the result of the difference in resulting harm, or of some unknown combination of the two.

The larger point here is when we law professors throw around hypotheticals, we often have little idea what the respondent is really responding to. This often is not a problem. We use hypotheticals in many ways, soinetimes just to inake a conceptual point in concrete form. The facts in the hypothetical nay just be convenient stand-ins for concepts. We are not relying upon the respondent's reaction as a truly reliable intuitive judgment of blameworthiness.

But in the argument by hypothetical that Professor Katz presents, he is indeed relying upon people's responses to his hypotheticals as being their true assessment of relative blameworthiness. And, indeed, those

20. See, e.g., Amos Tversky \& Daniel Kahneman, Judgment Under Uncertainty: Heuristics and Biases, in Judgment UNDER UNCERTAiNTY: Heuristics and Biases 3-22 (Daniel Kahneman et al. eds., 1982); Baruch Fischhoff, Hindsight $\neq$ Foresight: The Effect of Outcome Knowledge on Judgment Under Uncertainty, I J. EXP. PsYch. 288 (1975). 
blameworthiness judgments are the key to his argument. Whether or not his argument succeeds depends upon the blameworthiness judgments that he gets from his reader. But, without knowing how any reader in fact is perceiving his hypotheticals, without knowing what background or context a reader is assuming, we cannot know what the blameworthiness judgments mean.

The problem is aggravated by the often bizarre nature of Professor Katz's hypotheticals. Readers commonly fill in the facts they need to make the scenario connect with their own life experience. $Z$ hitting $Y$ with a stick may require a bit of "contextualizing" by the reader, as we have seen above. What exactly will our reader do when asked to envision Larry poisoning five people, then killing a sixth to get body parts for transplants? I do not think we know.

Frankly, it is likely that such a task-givmg an intuitive blameworthiness judgment in such a case-is beyond anyone's ability. (Perhaps it could be a meaningful question for a transplant surgeon?) The results we get, typically from other law professors, are probably not intuitive judgments of blameworthiness but more likely intellectualized answers generated by applying the professor's resident collection of theoretical positions-that is, whether resulting harm ought to be judged significant. If that is so, it is not likely that Professor Katz's arguments by hypothetical can have the force that he wishes.

\section{III}

THE ROLE OF INTUITION AND THE IMPLICATIONS OF ITS Use

Beyond the problem of reliably testing a reader's imtuitions of justice with hypotheticals, I have a larger concern about Professor Katz's use of intuition. Our intuitions are the driving force in Professor Katz's nonconsequentialist argument. In explaining the reason for his paper, he says:

Why not just admit that the law of attempt makes no sense? Why not just say that it deserves abolition, or maybe toleration, but hardly endorsement? Because despite its seeming nonsensicality, there is a strong and deep intuition that "outcome luck" (as the philosophers like to call it) matters. ${ }^{21}$

And Professor Katz's method of proving that harm matters is, as discussed in Part I, to show the nonbeliever that their nonbelief conflicts with other intuitions that they will think are more important, that is:

to show the greater wickedness of the successful assassin to follow from other dearly held moral intuitions that no one would want to do without. 22

21. Katz, supra note 1, at 792.

22. Id. at 794 . 
One has the sense that, under this view, nonconsequentialist arguments are a battle of intuitions. Can it be that the function of deontological theory is at times to justify our intuitions of justice? That its method of proof is to weigh the relative depth of intuitive feelings when our intuitions conflict?

Professor Katz is not alone in his use of intuition. Many scholars making nonconsequentialist claims rely upon intuitions. ${ }^{23}$ It is a common form of argument in our business, but it has always made me a bit uncomfortable.

Why should we assume that our emotional feelings in assessing blame will necessarily track the results of logical reasoning from principles of Right and Good? How we feel may be simply a product of genetic programming from long-term evolutionary forces-why are we repulsed by our feces?-or perhaps the product of environmental and social forceswhy do some people feel emotionally more comfortable with one social class or another? Nor is it comforting that our feelings are shared by many or most others in our group, as feudalism, slavery, and National Socialism remind us. Why, then, should our intuitions be evidence of any sort in establishing a deontological position? As a nonphilosopher, my assumption has always been that moral philosophers think that what they do is useful in large part because it founds a position on more than our feelings about an issue. Unlike other common forms of argument in which appeal to our feelings or intuitions may be persuasive, the philosopher shows one position to be better than another by showing that one logically follows from foundational primciples.

I think Professor Katz's mstincts are right that our shared intuitions of justice are important. It is for these reasons that I have worked to sort out precisely what those intuitions are, as in Justice, Liability, and Blame, ${ }^{24}$ noted earlier. But those empirical studies have primarily consequentialist significance. In our article, The Utility of Desert, ${ }^{25}$ we point out the crime control utility of having criminal law adjudication rules generally track the community's shared intuitions of justice. Such tracking can give the criminal law moral credibility with the community, which can enhance the law's crime control power in several ways. Increased moral authority can increase the criminal law's ability to shape moral norms, which may be the single most powerful force in controlling people's conduct. In a more direct way, increased moral authority increases the criminal law's ability to

23. See, e.g., 1 Paul H. Robinson, Criminal Law Defenses 23-24 (1984) (disputing George Fletcher's claim that full liability is intuitively prefcred). (The dispute apparcntly is resolved in Paul H. Robinson \& John M. Darley, Testing Competing Theories of Justification, 76 N.C. L. REv. 1095 (1998).)

24. See supra note 13.

25. Paul H. Robinson \& John M. Darley, The Utility of Desert, 91 Nw. U. L. REv. 453 (1997). 
dissuade people from conduct whose wrongfulness may be ambiguous in the mind of the actor. ${ }^{26}$

Thus, some of Professor Katz's arguments by hypothetical might be relevant to the utilitarian debate. If we want the criminal law to have moral credibility and if Katz can show us through his hypotheticals that certain rules conflict with (or correspond with) people's intuitions of justice, then we can learn how better to shape criminal law to increase its moral authority. But, when Professor Katz seeks to make a deontological argument, as he seems to want to do, there seems little reason why our intuitive reaction to a given hypothetical ought to be evidence of any sort.

\section{Summary OF CONCLUSIONS}

Let me summarize my conclusions. If one wishes to support a deontological conclusion, testing a reader's intuitions on a hypothetical cannot be used as evidence to prove the point. Even if it could, Professor Katz's hypotheticals, and all such "cowboy" testing, as it might be called, produce unreliable results about people's intuitions of blameworthiness. The barer the hypothetical, and especially the more loopy and disconnected with reality, the more unreliable the result. Even if intuitions mattered in deontological arguments, and even if Professor Katz's testing of intuition was reliable, the arguments he presents fail to offer one who does not believe in the significance of resulting harm a reason why he or she must treat an attempt the same as the completed offense. The arguments may create for nonbelievers some uncertainty and confusion in the application of the concurrence requirement (an uncertainty and confusion in application shared to some extent with believers), but such uncertainty, which is little different from so many other uncertainties in application of rules to facts, seems to offer little reason to the nonbeliever to convert. Thus, even though I share in Katz's underlying beliefs, I doubt that his arguments will succeed in convincing anyone who does not already believe in the significance of resultimg harm.

26. See id. at 457-58 (describing how criminal law shapes and sustains social norms and ideals of justice). 
[Vol. 88:813 